\title{
Electrical resistivity measurements to predict abrasion resistance of rock aggregates
}

\author{
SAIR KAHRAMAN* and MUSTAFA FENER ${ }^{\dagger}$ \\ Mining Engineering Department, ${ }^{\dagger}$ Geological Engineering Department, Nigde University, 51100 Nigde, Turkey
}

MS received 26 October 2007; revised 11 December 2007

\begin{abstract}
The prediction of Los Angeles (LA) abrasion loss from some indirect tests is useful for practical applications. For this purpose, LA abrasion, electrical resistivity, density and porosity tests were carried out on 27 different rock types. LA abrasion loss values were correlated with electrical resistivity and a good correlation between the two parameters was found. To see the effect of rock class on the correlation, regression analysis was repeated for igneous rocks, metamorphic rocks and sedimentary rocks, respectively. It was seen that correlation coefficients were increased for the rock classes. In addition, the data were divided into two groups according to porosity and density, respectively. After repeating regression analysis for these porosity and density groups, stronger correlations were obtained compared to the equation derived for all rocks. The validity of the derived equations was statistically tested and it was shown that all derived equations were significant. Finally, it can be said that all derived equations can alternatively be used for the estimation of LA abrasion loss from electrical resistivity.
\end{abstract}

Keywords. LA abrasion loss; electrical resistivity; density; porosity.

\section{Introduction}

Different rocks such as igneous, metamorphic and sedimentary are used as aggregates in a wide variety of applications including portland cement concrete and asphalt production, road/rail base, drainage systems etc. Due to increasing expansion of highway and other construction works and decreasing natural aggregate resources in the world, the demand for crushed stone aggregates has increased from day-to-day.

One of the important properties of rock aggregates is abrasion resistance. The abrasion resistance of aggregates is generally tested using the Los Angeles (LA) testing machine. The procedure of LA abrasion test is relatively simple. However, it is time consuming and expensive compared to the indirect tests. Electrical resistivity measurement which is a non-destructive geophysical method is a very easy test to carry out and requires less rock sample. If a strong relation between LA abrasion loss and electrical resistivity are found, it can be used for the prediction of the abrasion resistance of aggregates especially for preliminary investigations.

The main objective of this work is to investigate the possibility of estimating the abrasion resistance of aggregates from electrical resistivity measurements.

*Author for correspondence (sairkahraman@yahoo.com)

\section{Previous studies}

Some investigations were carried out by different researchers to correlate LA abrasion loss with rock properties. A strong correlation between the compressive strength determined by the Schmidt hammer and LA abrasion loss for the Saudi Arabian aggregate near the city of Jeddah was obtained by Kazi and Al-Mansour (1980). Ballivy and Dayre (1984) found an inverse relation between the compressive strength and LA abrasion loss for limestones, the degree of correlation being different for different types of limestones. The porous limestones showed strong correlation, whereas the correlation for the massive, less porous limestones varied as a function of grain size. The coarsegrained or crystalline limestones showed a higher percentage loss due to abrasion than the fine-grained limestones of the same compressive strength. A non-linear inverse relation between the compressive strength and LA abrasion loss divided by dry density was established by Cargill and Shakoor (1990). The decrease in percentage loss with increasing strength is much more rapid at strength values below $100 \mathrm{MPa}$ than at higher strength values. Multivariate regression analysis between compressive strength and LA loss, dry density, and absorption for carbonate rocks was performed by Shakoor and Brown (1996). They obtained a statistically significant correlation which can be used to predict unconfined compressive strength. Kasim and Shakoor (1996) found strong correlations between degradation and LA abrasion loss for dry sandstones, 
Table 1. Location and name of the rocks sampled.

\begin{tabular}{rlll}
\hline Rock code & \multicolumn{1}{c}{ Location } & \multicolumn{1}{c}{ Rock type } & Rock class \\
\hline 1 & Altinhisar/Nigde & Basalt & Igneous \\
2 & Uckapili/Nigde & Granite & Igneous \\
3 & Ortakoy/Aksaray & Granite (Anadolu grey) & Igneous \\
4 & Kaman/Kirsehir & Granite (Kaman Rosa) & Igneous \\
5 & Kaman/Kirsehir & Granite (Kircicegi) & Igneous \\
6 & Gumusler/Nigde & Quartzite & Metamorphic \\
7 & Gumusler/Nigde & Marble & Metamorphic \\
8 & Uckapili/Nigde & Marble & Metamorphic \\
9 & Altindag/Kütahya & Marble & Metamorphic \\
10 & Iscehisar/Afyon & Marble & Metamorphic \\
11 & Yatagan/Muğla & Marble & Metamorphic \\
12 & Gumusler/Nigde & Amphibolschist & Metamorphic \\
13 & Gumusler/Nigde & Gneiss & Metamorphic \\
14 & Gumusler/Nigde & Micaschist & Metamorphic \\
15 & Gumusler/Nigde & Migmatite & Metamorphic \\
16 & Kilavuzkoy/Nigde & Serpentinite & Metamorphic \\
17 & Sogutalan/Bursa & Limestone & Sedimentary \\
18 & Yahyali/Kayseri & Dolomitic limestone & Sedimentary \\
19 & Bunyan/Kayseri & Limestone (Bunyan Rosa) & Sedimentary \\
20 & Yildizeli/Sivas & Travertine & Sedimentary \\
21 & Finike/Antalya & Travertine (Limra) & Sedimentary \\
22 & Bucak/Burdur & Travertine (Limra) & Sedimentary \\
23 & Demre/Antalya & Travertine (Demre stone) & Sedimentary \\
24 & Demre/Antalya & Travertine (Limra) & Sedimentary \\
25 & Godene/Konya & Travertine & Sedimentary \\
26 & Mut/Icel & Travertine & Sedimentary \\
27 & Karaman & Travertine & Sedimentary \\
\hline & & &
\end{tabular}

saturated sandstones and igneous/metamorphic rocks. AlHarthi (2001) tested Saudi Arabian rocks and correlated LA abrasion loss with both UCS and point load index. He showed that LA abrasion loss decreases with increasing UCS and point load index. Kahraman and Fener (2007) tested 35 different rock types to investigate the relation between UCS and LA abrasion loss. They found a good correlation between LA abrasion loss and UCS. In addition, they showed that when the rocks were classified into classes according to porosity, the correlation coefficients were increased. Kahraman and Gunaydin (2007) investigated the possibility of predicting LA abrasion loss from Schmidt hammer and point load index. They concluded that LA abrasion loss of aggregates can reliably be estimated from point load index. The estimation of LA abrasion loss from Schmidt hammer value is not strong as compared to point load index, however, it is in the acceptable limits.

\section{Sampling}

Quarries, granite and marble factories, and natural outcrops in Nigde, Kayseri, Konya and Antalya areas of Turkey were visited and rock blocks were collected. A total of 27 different rock types were sampled, 5 of which were igneous, 11 were metamorphic and 11 were sedimentary. Each block sample was inspected for macro- scopic defects so that it would provide test specimens free from fractures, partings or alteration zones. The location and the name of the rocks are given in table 1 .

\section{Laboratory studies}

\subsection{Los Angeles abrasion test}

ASTM method C 131-66 was used for LA abrasion test. Test samples were oven-dried at $105-110^{\circ} \mathrm{C}$ for $24 \mathrm{~h}$ and then cooled to room temperature before they were tested. There are four aggregate size gradings to choose from in the ASTM method. Grading D was used in the tests. Eight steel spheres were placed in a steel drum along with $\sim 5000 \mathrm{~g}$ aggregate sample and the drum was rotated for 500 times at a rate of $30-33 \mathrm{rev} / \mathrm{min}$. After the revolution was complete, the sample was sieved through the no. 12 sieve $(1.7 \mathrm{~mm})$. The amount of material passing the sieve, expressed as a percentage of the original weight, is the LA abrasion loss or percentage loss.

\subsection{Electrical resistivity measurements}

For most rocks where current is carried by ions in the pore fluid the resistivity depends on porosity, pore fluid resistivity (salinity), pore fluid saturation, clay content, temperature and pressure. In all tests conducted in this study, 
Table 2. Results of tests

\begin{tabular}{rrccc}
\hline Rock code & Electrical resistivity $(\Omega \cdot \mathrm{m})$ & LA abrasion loss $(\%)$ & Density $\left(\mathrm{g} / \mathrm{cm}^{3}\right)$ & Porosity $(\%)$ \\
\hline 1 & $1558 \cdot 7$ & $17 \cdot 2$ & $2 \cdot 58$ & $5 \cdot 50$ \\
2 & $848 \cdot 4$ & $15 \cdot 7$ & $2 \cdot 63$ & $1 \cdot 15$ \\
3 & $849 \cdot 9$ & $33 \cdot 7$ & $2 \cdot 55$ & $0 \cdot 62$ \\
4 & $386 \cdot 9$ & $40 \cdot 3$ & $2 \cdot 61$ & $0 \cdot 63$ \\
5 & $627 \cdot 9$ & $34 \cdot 7$ & $2 \cdot 47$ & $0 \cdot 98$ \\
6 & $1193 \cdot 6$ & $20 \cdot 2$ & $2 \cdot 72$ & $0 \cdot 85$ \\
7 & $552 \cdot 4$ & $45 \cdot 5$ & $2 \cdot 68$ & $0 \cdot 79$ \\
8 & $859 \cdot 1$ & $40 \cdot 6$ & $2 \cdot 69$ & $0 \cdot 37$ \\
9 & $745 \cdot 2$ & $28 \cdot 8$ & $2 \cdot 67$ & $0 \cdot 06$ \\
10 & $415 \cdot 2$ & $47 \cdot 2$ & $2 \cdot 62$ & $0 \cdot 13$ \\
11 & $271 \cdot 5$ & $23 \cdot 2$ & $2 \cdot 61$ & $0 \cdot 30$ \\
12 & $711 \cdot 4$ & $40 \cdot 5$ & $2 \cdot 69$ & $1 \cdot 90$ \\
13 & $366 \cdot 9$ & $37 \cdot 7$ & $2 \cdot 70$ & $0 \cdot 79$ \\
14 & $588 \cdot 0$ & $16 \cdot 6$ & $2 \cdot 75$ & $1 \cdot 95$ \\
15 & $761 \cdot 8$ & $15 \cdot 9$ & $2 \cdot 49$ & $1 \cdot 33$ \\
16 & $2014 \cdot 2$ & $33 \cdot 3$ & $2 \cdot 75$ & $0 \cdot 91$ \\
17 & $580 \cdot 9$ & $25 \cdot 0$ & $2 \cdot 56$ & $0 \cdot 69$ \\
18 & $759 \cdot 6$ & $24 \cdot 7$ & $2 \cdot 58$ & $0 \cdot 31$ \\
19 & $661 \cdot 5$ & $31 \cdot 4$ & $2 \cdot 57$ & $0 \cdot 93$ \\
20 & $336 \cdot 4$ & $42 \cdot 3$ & $2 \cdot 4$ & $3 \cdot 12$ \\
21 & $50 \cdot 0$ & $75 \cdot 9$ & $2 \cdot 31$ & $5 \cdot 93$ \\
22 & $9 \cdot 9$ & $54 \cdot 5$ & $2 \cdot 13$ & $12 \cdot 57$ \\
23 & $272 \cdot 8$ & $45 \cdot 3$ & $2 \cdot 39$ & $2 \cdot 15$ \\
24 & $10 \cdot 9$ & $40 \cdot 1$ & $2 \cdot 09$ & $13 \cdot 27$ \\
25 & $311 \cdot 8$ & $61 \cdot 9$ & $2 \cdot 33$ & $4 \cdot 08$ \\
26 & $11 \cdot 7$ & $39 \cdot 0$ & $1 \cdot 93$ & $8 \cdot 74$ \\
27 & $178 \cdot 9$ & & $2 \cdot 29$ & $4 \cdot 04$ \\
\hline
\end{tabular}

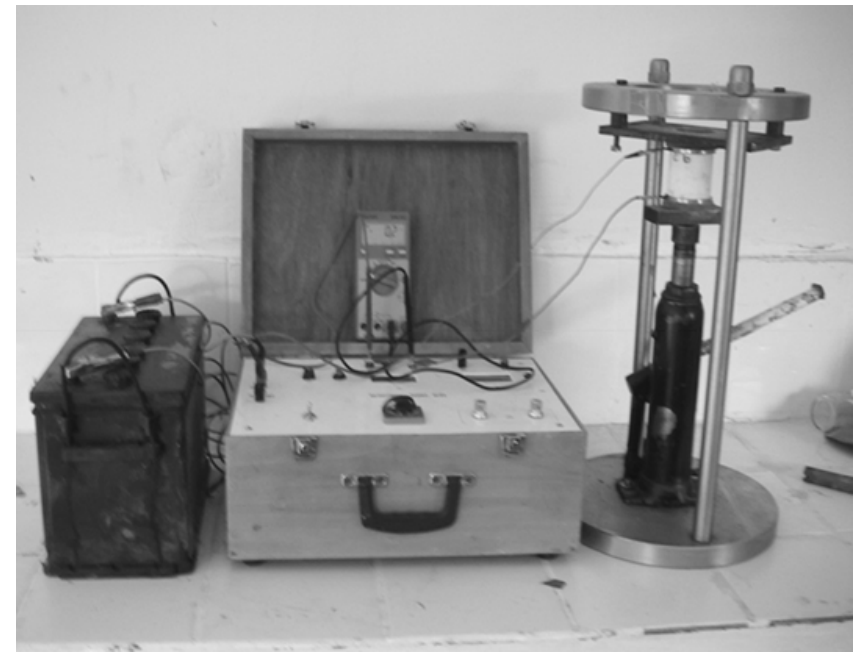

Figure 1. Resistivity measurement system.

pore fluid salinity, pore fluid saturation, temperature and pressure were kept the same.

Resistivity measurements were performed on cylindrical samples of $54.4 \mathrm{~mm}$ diameter and $\sim 50 \mathrm{~mm}$ length. Axial end surfaces of the samples were ground flat and parallel. The samples were fully saturated with brine ( $\mathrm{NaCl}$ solution) consisting of distilled water and a $2 \%$ by weight high-purity salt. Saturation was controlled by measurement of weight increase. The samples were assumed fully saturated when no additional increase in weight was observed. The brine resistivity was $0.58 \Omega \cdot \mathrm{m}$ at room temperature.

A resistivity meter was used for the resistivity measurements. The samples were fixed between electrodes using a hydraulic ram (figure 1). Circular stainless steel electrodes were used in the tests in which two-electrode technique was employed. To ensure a good contact between electrodes and samples, a pad of filter paper soaked with brine solution was placed between the core and the steel electrodes.

At least three samples were tested for each rock types and three different voltage levels were applied for each sample. Using the readings of current and voltage drop and the geometry of the samples, resistivity values were calculated from the following equation

$$
\rho=\frac{R A}{L},
$$

where $\rho$ is the electrical resistivity, $R$ the resistance, $A$ the cross sectional area of specimen, and $L$ the length of specimen.

\subsection{Density test}

Trimmed core samples were used in the determination of dry density. The specimen volume was calculated from 
an average of several calliper readings. The weights of the specimens were determined by a balance, capable of weighing to an accuracy of $0 \cdot 1$ of the sample weight. The density values were obtained from the ratio of the specimen weight to the specimen volume.

\subsection{Porosity test}

Porosity values were determined using saturation and calliper techniques. Pore volumes were calculated from dry and saturated weights and sample volumes were obtained from calliper readings. The porosity values were obtained from the ratio of the pore volume to the specimen volume.

\section{Statistical analysis and discussion}

All test results are given in table 2. The results were analysed for the estimation of LA abrasion loss from electrical

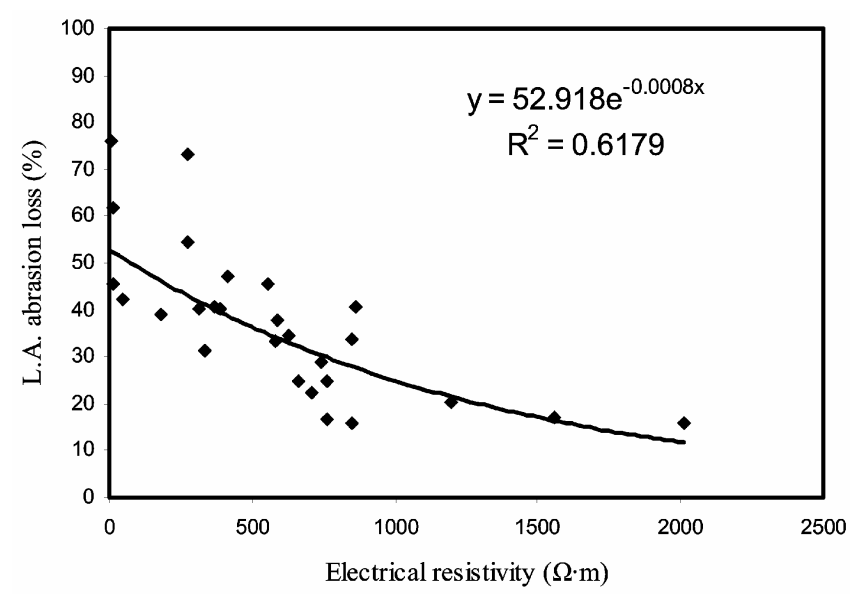

Figure 2. Relation between LA abrasion loss and electrical resistivity for all rocks.

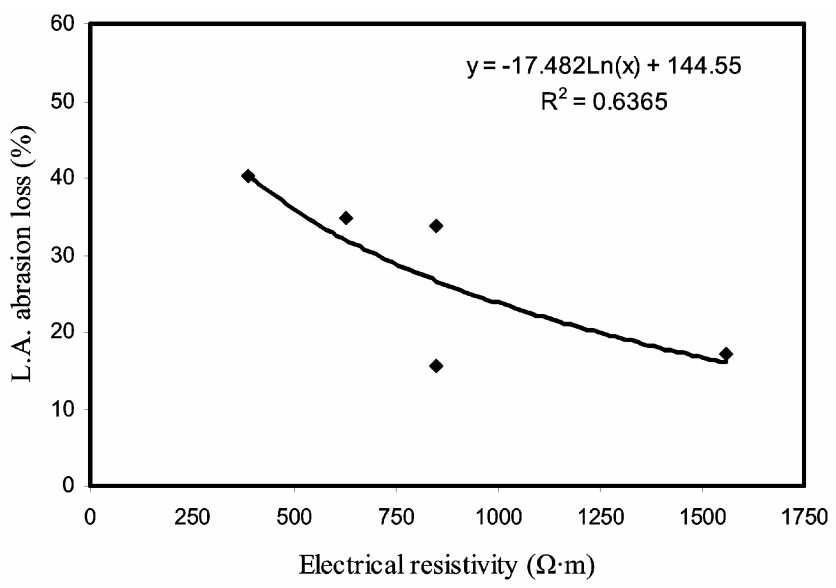

Figure 3. Relation between LA abrasion loss and electrical resistivity for igneous rocks. resistivity using the method of least squares regression. Linear, logarithmic, exponential and power curve fitting approximations were tried and the best approximation equation with highest correlation coefficient was determined for each regression.

Firstly, LA abrasion loss values were correlated with corresponding electrical resistivity values and a good correlation was obtained. An exponential relation was found between LA abrasion loss and electrical resistivity (figure 2). The equation of the curve is

$$
\mathrm{LA}=52.92 e^{-0.0008 \rho}, \quad r^{2}=0.62 \text {, }
$$

where LA is the LA abrasion loss (\%) and $\rho$ the electrical resistivity $(\Omega \cdot \mathrm{m})$.

To see how the correlation varies with the rock class, regression analysis was performed for igneous rocks, metamorphic rocks and sedimentary rocks, respectively (figures 3-5). The equations of the curves are:

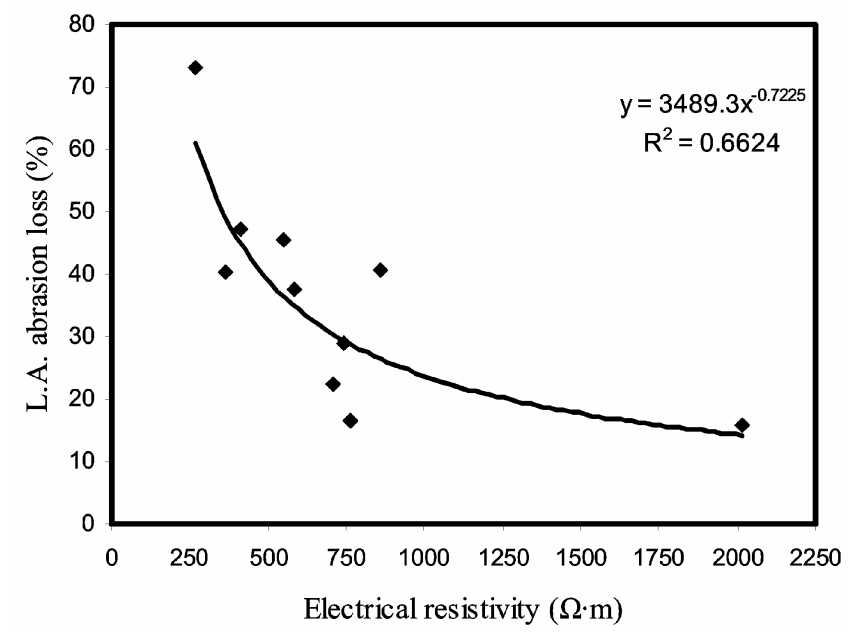

Figure 4. Relation between LA abrasion loss and electrical resistivity for metamorphic rocks.

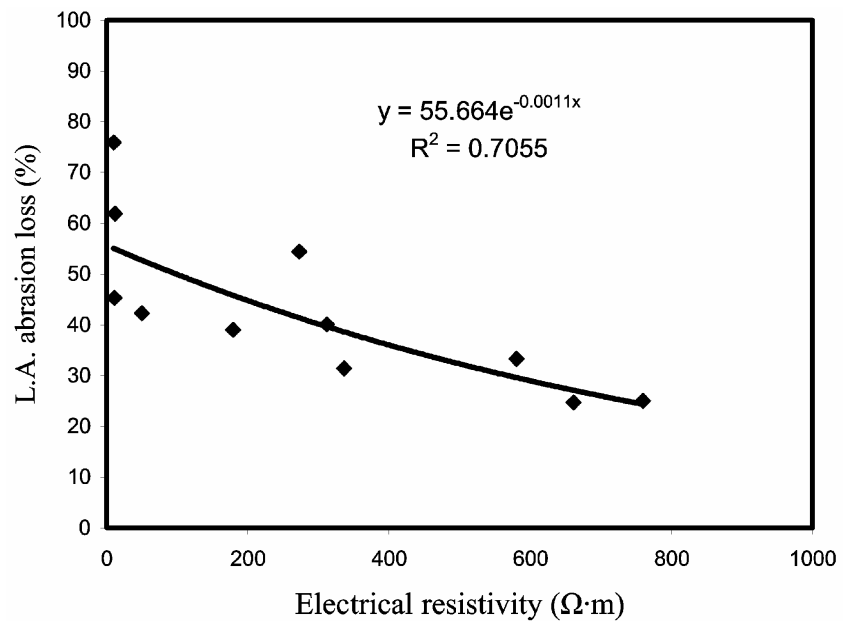

Figure 5. Relation between LA abrasion loss and electrical resistivity for sedimentary rocks. 
for igneous rocks,

$$
\mathrm{LA}=-17 \cdot 48 \ln \rho+144 \cdot 55, \quad r^{2}=0.64,
$$

for metamorphic rocks,

$$
\mathrm{LA}=3617 \cdot 6 \rho^{-0.73}, \quad r^{2}=0.69,
$$

for sedimentary rocks,

$$
\mathrm{LA}=55.66 e^{-0.0011 \rho}, \quad r^{2}=0.71 .
$$

As shown in (2)-(4), the correlation coefficients for all rock classes were increased compared to (1). That the correlation coefficient for igneous rocks was increased less was probably due to the scarcity of the data.

To check the possibility of obtaining more significant relations, the tested rocks were divided into two groups according to porosity ( $n$ ) values: $n<1 \%$ and $n>1 \%$, and two groups according to density $(\gamma)$ values: $\gamma<2.60 \mathrm{~g} / \mathrm{cm}^{3}$ and $\gamma>2.60 \mathrm{~g} / \mathrm{cm}^{3}$. Regression analysis was repeated for these porosity and density groups and stronger correlations

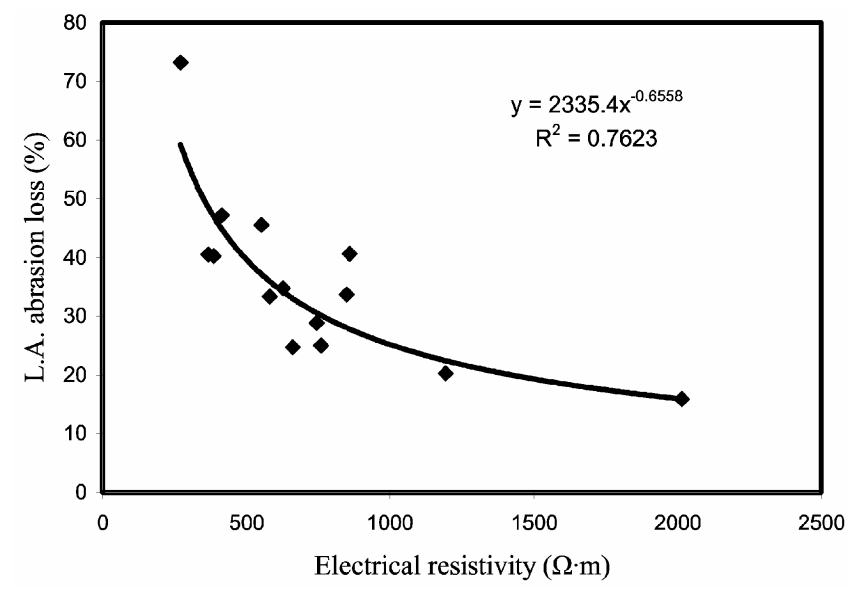

Figure 6. Relation between LA abrasion loss and electrical resistivity for porosity, $<1 \%$.

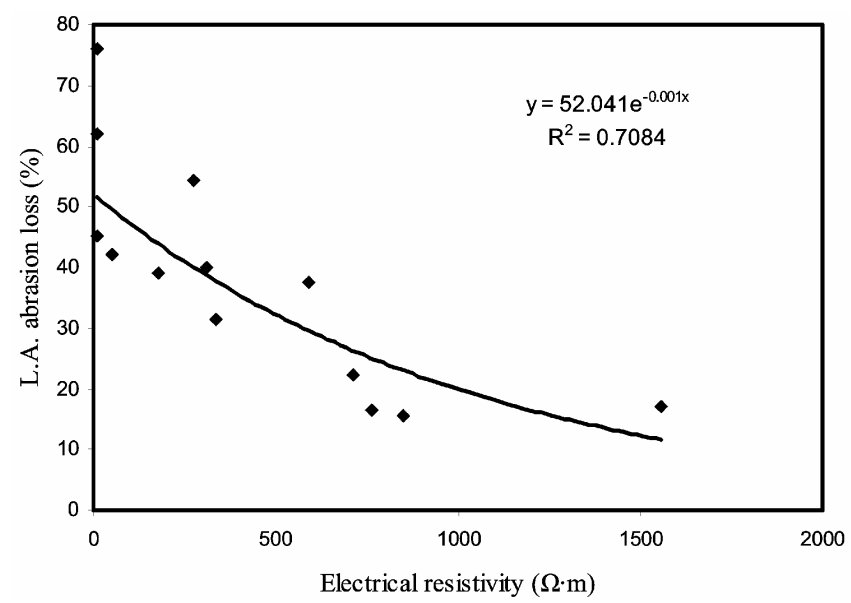

Figure 7. Relation between LA abrasion loss and electrical resistivity for porosity, $>1 \%$. compared to (1) were obtained (figures 6-9). The equations of the curves are:

for $n<1 \%$,

$$
\mathrm{LA}=2335.4 \rho^{-0.66}, \quad r^{2}=0.76,
$$

for $n>1 \%$,

$$
\mathrm{LA}=52.04 e^{-0.001 \rho}, \quad r^{2}=0.71,
$$

for $\gamma<2.60 \mathrm{~g} / \mathrm{cm}^{3}$,

$$
\mathrm{LA}=-7 \cdot 81 \rho+80 \cdot 08, \quad r^{2}=0 \cdot 69,
$$

for $\gamma>2.60 \mathrm{~g} / \mathrm{cm}^{3}$,

$$
\mathrm{LA}=3402.9 \rho^{-0.72}, \quad r^{2}=0.71 \text {. }
$$

An important point is that one should be careful when using the derived equations. The pore fluid resistivity is $0.58 \Omega \cdot \mathrm{m}$ at room temperature in all tests. The role of pore fluids in the electrical resistivity values of rocks is

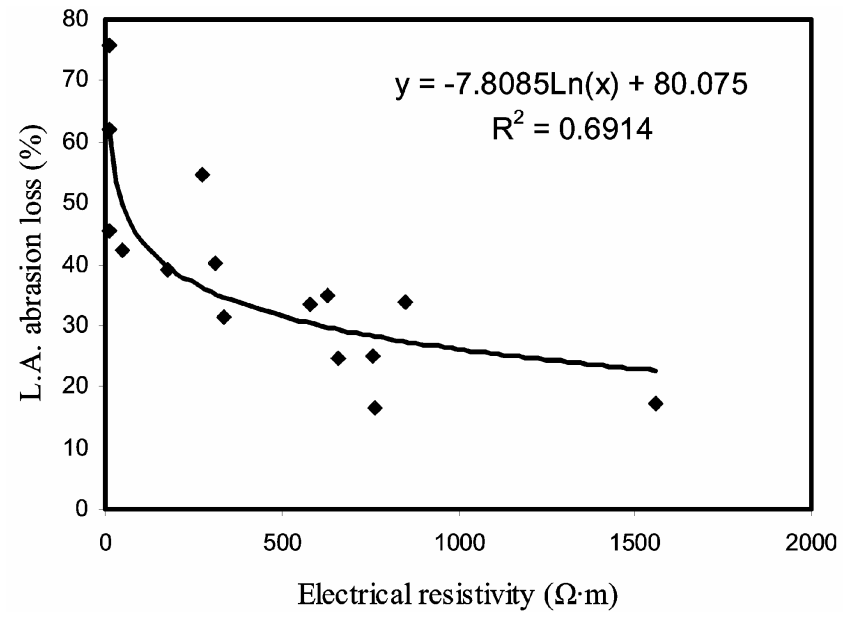

Figure 8. Relation between LA abrasion loss and electrical resistivity for density, $<2.60 \mathrm{~g} / \mathrm{cm}^{3}$.

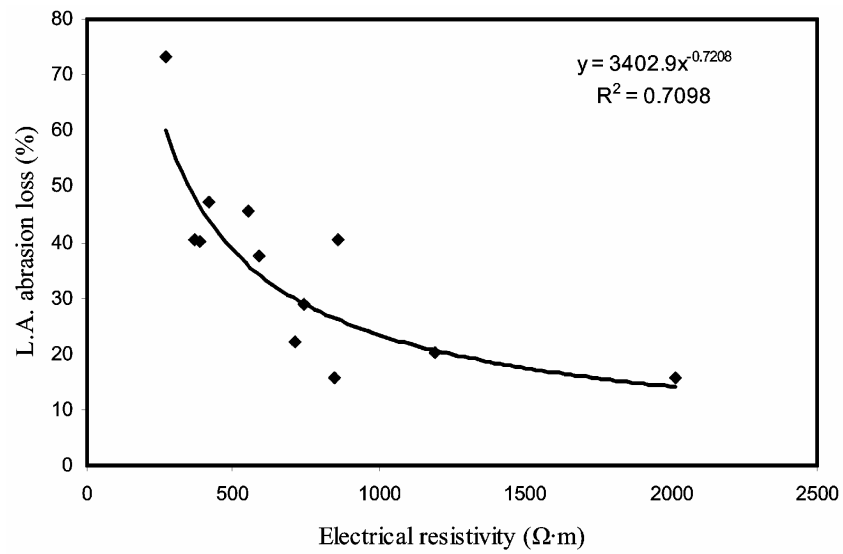

Figure 9. Relation between LA abrasion loss and electrical resistivity for density, $>2.60 \mathrm{~g} / \mathrm{cm}^{3}$. 
Table 3. $t$ - and $F$-test results

\begin{tabular}{lcccc}
\hline Equation no. & $t$-tabulated & $t$-test & $F$-tabulated & $F$-test \\
\hline 1 & \pm 1.71 & -6.05 & 4.02 & 38.50 \\
2 & \pm 2.13 & -4.14 & 5.32 & 17.81 \\
3 & \pm 1.81 & 4.91 & 4.35 & $25 \cdot 22$ \\
4 & \pm 1.81 & 2.86 & 4.35 & 8.88 \\
5 & \pm 1.77 & 5.80 & 4.23 & $35 \cdot 16$ \\
6 & \pm 1.78 & 3.07 & 4.26 & $10 \cdot 00$ \\
7 & \pm 1.76 & 3.77 & 4.20 & $15 \cdot 02$ \\
8 & \pm 1.80 & 5.03 & 4.30 & 26.59 \\
\hline
\end{tabular}

very important. Bulk resistivity of rocks largely depends on the electrical resistivity of pore fluid. This can be seen from the Archie's well known empirical relation between the ratio of rock resistivity to the pore fluid resistivity, called the formation factor, and the fractional porosity for the fully saturated and clay free rocks (Archie 1942). On the other hand, Keller and Frischknecht (1966) investigated the relation between salinity and solution resistivity for solutions of a variety of salts, all at $18^{\circ} \mathrm{C}$. They found that the solution resistivity linearly decreases with increasing salinity on log-log plot. Kermabon et al (1969) indicated that bulk conductivity of rock linearly increases with increasing conductivity of soaking solution. David and Marot (1989) found a nonlinear relation between rock conductivity and pore fluid conductivity on $\log -\log$ plot.

\section{Validation of derived models}

As shown above, the correlation coefficients of the all equations are good, but they do not necessarily identify the valid model. Validation of the equations was checked by the $F$-test and the $t$-test. The statistical results of the two equations are given in table 2 .

The significance of $R^{2}$-values can be determined by the $t$-test, assuming that both variables are normally distributed and the observations are chosen randomly. The test compares computed $t$-value with tabulated $t$-value using the null hypothesis. In this test, a $95 \%$ level of confidence was chosen. If the computed $t$-value is greater than tabulated $t$-value, the null hypothesis is rejected. This means that $r$ is significant. If the computed $t$-value is less than tabulated $t$-value, the null hypothesis is not rejected. In this case, $r$ is not significant. As seen in table 3, the computed $t$-values are greater than tabulated $t$-values for all equations, suggesting all models are valid.

The significance of regressions was determined by analysis of variance. In this test, a $95 \%$ level of confidence was chosen. If the computed $F$-value is greater than tabulated $F$-value, the null hypothesis is rejected and there is a real relation between dependent and independent variables. Since the computed $F$-values are greater than tabulated $F$-values in all the equations, the null hypothesis is rejected (table 3). Therefore, it is concluded that all models are valid.

\section{Conclusions}

LA abrasion, electrical resistivity, density and porosity tests were carried out on 27 different rock types. The results were statistically analysed and some predictive models for the LA abrasion loss were developed. A good correlation between LA abrasion loss and electrical resistivity was found for all rocks. When the regression analysis was repeated for rock classes, correlation coefficients were increased. In addition, the data were divided into two groups according to porosity and density, respectively. Regression analysis was repeated for these porosity and density groups and generally stronger correlations were obtained.

All alternative models derived for the estimation of LA abrasion loss from electrical resistivity are strong and statistically significant. It was concluded that LA abrasion loss of aggregates can reliably be estimated from electrical resistivity.

\section{Acknowledgement}

This work has been partially supported by the Turkish Academy of Sciences, in the framework of the Young Scientist Award Program (EA-TUBA-GEBIP/2001-1-1).

\section{References}

Al-Harthi A A 2001 Bull. Eng. Geol. Environ. 60193

Archie G E 1942 Trans. Am. Inst. Min. Metall. Petrol Eng. 146 54

Ballivy G and Dayre M 1984 Int. Ass. Eng. Geol. Bull. 29339

Cargill J S and Shakoor A 1990 Int. J. Rock Mech. Min. Sci. 27 495

David C and Marot M 1989 Proc. ISRM-SPE int. symp. rock at great depth (Rotterdam: Balkema) Vol. 1, pp 203-209

Kahraman S and Fener M 2007 Mater. Lett. 614861

Kahraman S and Gunaydin O 2007 Bull. Eng. Geol. Environ. 66 449

Kasim M and Shakoor A 1996 Eng. Geol. 44213

Kazi A and Al-Mansour L R 1980 Q. J. Eng. Geol. 1345

Keller G V and Frischknecht F C 1966 Electrical methods in geophysical prospecting (New York: Pergamon Press)

Kermabon A, Gehin C and Blavier P 1969 Geophys. 34554

Shakoor A and Brown C L 1996 Int. Ass. Eng. Geol. Bull. 5398 